\title{
Impact of Acridine Orange in Patients With Soft Tissue Sarcoma Treated With Marginal Resection
}

\author{
HIROYUKI TSUCHIE ${ }^{1}$, MAKOTO EMORI ${ }^{2}$, NAOHISA MIYAKOSHI ${ }^{1}$, \\ HIROYUKI NAGASAWA ${ }^{1}$, KYOJI OKADA $^{3}$, YASUTAKA MURAHASHI ${ }^{2}$, EMI MIZUSHIMA ${ }^{2}$, \\ JUNYA SHIMIZU $^{2}$, TOSHIHIKO YAMASHITA ${ }^{2}$ and YOICHI SHIMADA ${ }^{1}$ \\ ${ }^{1}$ Department of Orthopedic Surgery, Akita University Graduate School of Medicine, Akita, Japan; \\ ${ }^{2}$ Department of Orthopedic Surgery, Sapporo Medical University School of Medicine, Sapporo, Japan; \\ ${ }^{3}$ Department of Physical Therapy, Akita University Graduate School of Health Sciences, Akita, Japan
}

\begin{abstract}
Background/Aim: Although few studies have shown the effectiveness of adjuvant therapy with acridine orange (AO) for soft tissue sarcoma (STS) patients, no study has investigated this among cases with marginal resection. The aim of the study was to evaluate the effectiveness of $A O$ therapy directly by comparing it to marginal resection cases that did not receive AO. Patients and Methods: This retrospective study included 19 and 33 patients with STS who received $A O$ therapy ( $A O$ group) and marginal resection without $A O$ therapy (non-AO group), respectively. The patients' clinical information was collected, and the clinical courses were compared. Results: The local recurrence rate in the $A O$ group was significantly lower than that in the non$A O$ group $(p<0.05)$. The local recurrence-free survival curves significantly differed between the two groups $(p<0.05)$. High grade malignancy and no treatment with $A O$ were identified as risk factors for local recurrence $(p<0.05)$. Conclusion: $A O$ therapy strongly suppressed local recurrence after marginal resection of STS.
\end{abstract}

Soft tissue sarcoma (STS) is relatively rare compared with other types of cancer. Radical resection with adequate margin is important in the treatment of STS for the prevention of local recurrence. However, when tumors are in contact with important tissues such as major nerves and blood vessels, removal of these important tissues causes serious dysfunctions. Conversely, if resection is conducted

Correspondence to: Hiroyuki Tsuchie, MD, Department of Orthopedic Surgery, Akita University Graduate School of Medicine, 1-1-1 Hondo, Akita 010-8543, Japan. Tel: +81 188846148, Fax: +81 188362617, e-mail: tuchikiti@yahoo.co.jp ORCID: 0000-0001-5011-7184

Key Words: Acridine orange, marginal resection, soft tissue sarcoma. in the area where the tumor is in contact with the tissue, the recurrence rate increases. In such cases, radiation therapy is one of adjuvant therapies; it may be effective in reducing local recurrence rate without serious dysfunction $(1,2)$. However, adjuvant radiotherapy can also cause various conditions that could lead to dysfunction, such as fibrosis, edema, and other pathological fractures $(1,3)$. Therefore, it is expected that adjuvant therapy will assist in suppressing local recurrence and hindering local dysfunction.

Kusuzaki et al. were the first to report the effectiveness of acridine orange (AO) treatment as an adjuvant therapy in STS; their research team has reported its effectiveness in various different studies (4-10). AO accumulates in acidic environments. As sarcoma cells have many large acidic vesicles, AO specifically binds to malignant tumors and immediately accumulates in tumor cells after local administration (11-15). AO has a strong cell destruction effect on tumor cells after a single session of blue light excitation or low-dose radiation, and residual tumor cells after tumor resection are killed.

Comparisons of STS cases in which extensive resection surgery was or was not performed have shown the efficacy of AO therapy $(7,8)$. However, there has been no report directly comparing whether or not AO should be used after marginal resection.

The aim of this study was to clarify the effectiveness of AO therapy in the treatment of STS.

\section{Patients and Methods}

Subjects. Twenty patients with initial STS involving the extremities or trunk were treated with AO therapy after surgical resection conducted in the Akita University Hospitals, in the Akita prefecture in Japan, between December 2004 and December 2014. We performed surgical treatment with $\mathrm{AO}$ on patients with indications that the tumor was in contact with major nerves or vessels, bones, and/or major organs, who did not show signs of massive invasion 
upon image evaluation before surgery. We defined resection through the capsule of the tumor as marginal resection and resection through the tumor as intralesional resection. Although tumor cells remained after employment of both methods, intralesional resection leaved behind more tumor cells. Only one patient who received intralesional resection among the 20 patients treated with AO therapy was excluded. Finally, 19 consecutive patients with STS treated with AO therapy, with a mean age of 64.4 years (range $=52$ 87 years), were included in this study (AO group). On the other hand, we retrospectively investigated the clinical and pathological data of STS patients with partial marginal resection without AO therapy and adjuvant radiotherapy, and we defined these patients as the control group (non-AO group). We enrolled 33 consecutive patients, with a mean age of 58.4 years (range=32-93 years), with initial STS involving the extremities or trunk who received marginal resection in the Akita University Hospital and Sapporo Medical University Hospital between January 1997 and April 2017 in the non-AO group.

This study was approved by the Institutional Review Board for Clinical Research at Akita University (approval number: 221), and informed consent was obtained from all patients.

Data variables and definitions. The patients' information, including: age, sex, tumor type, anatomical location of the tumor, size, metastasis at diagnosis, stage of the primary tumor, local and distant relapse, follow-up period, and outcomes were collected. The stage of the primary tumor was determined based on the staging system of the American Joint Committee on Cancer (AJCC), 7th edition (16). The specimens were classified using the French Federation of Cancer Center Sarcoma Group (FNCLCC) classification. This classification is based on the mitotic index, necrosis extension, and histological differentiation of the tumor (17). In the absence of death event, the date of the last follow-up was considered as the end of the follow-up period. The local recurrence-free survival (LRS) was defined as the time remaining free of local recurrence after the primary tumor had been resected. Overall survival (OS) was defined as the time period from the date of diagnosis to that of death or the last follow-up. As there were no deaths due to postoperative complications in this study, we defined death from original disease as died of disease (DOD). Cases were regarded to have a surgical indication if all lesions, including distant metastases, could be excised and if general anesthesia could be administered by an anesthesiologist.

Procedures for AO therapy. We conducted AO therapy, including photodynamic surgery (PDS), photodynamic therapy (PDS), and radiodynamic therapy (RDT), according to previously reported methods (4-9). After we performed marginal resections of STS, microscopic curettage was conducted using an ultrasonic surgical knife (Olympus Co. Ltd., Tokyo, Japan). During microscopic resection, we used a high-power xenon lamp $(500 \mathrm{~mW},>100,000$ $1 \mathrm{x})$ and special interference and resorption filters $(450-490 \mathrm{~nm})$ to select the blue light emitted by a xenon lamp (PDS). We sprayed a $1 \mu \mathrm{g} / \mathrm{ml}$ solution of AO (Sigma Aldrich Co, St Louis, MO, USA) on the resected surfaces, and microscopic curettage was repeated until the green AO fluorescence area representing the remaining tumor cells disappeared completely. PDT was followed by PDS. PDT was subsequently applied to the resected area of the tumor by illuminating it with $>100,000 \mathrm{~lx}$ of unfiltered light from a xenon lamp for $10 \mathrm{~min}$. The final step of RDT was performed in patients who agreed to undergo RDT. After closure of the surgical wound, without washing of the AO solution, a single-session of radiotherapy with 5 Gy was immediately administered to the resected area. Although, the policy was to conduct RDT in all cases, we did not conduct RDT when patients did not want it or when the radiation room could not be used immediately after surgery.

Statistical analysis. The clinical courses and results between the AO and the non-AO groups were compared. Furthermore, we investigated these factors in patients with high-grade sarcoma only. Additionally, we examined the factors affecting the local recurrence and patient prognosis.

All continuous variables were expressed as means \pm standard deviations (SD). Student's $t$-tests, Welch t-tests, and Chi Squared $\left(\chi^{2}\right)$ tests were used to compare characteristics between the two groups. The curves for LRS and OS were drawn using the KaplanMeier method, and differences were analyzed using the Long-rank test. A Cox proportional hazards model was used to identify the factors associated with local recurrence and prognosis. Probability ( $p$ ) values less than 0.05 were considered significant.

\section{Results}

Metastasis at diagnosis was observed in lymph nodes in only one patient among the non-AO group. According to the AJCC staging system, $0(0 \%), 4(21.1 \%), 1(5.2 \%), 2$ $(10.5 \%)$, and $12(63.5 \%)$ patients were classified as IA, IB, IIA, II B, and III in the AO group, respectively. In the nonAO group, 1 (3.0\%), 10 (30.3\%), 4 (12.2\%), 8 (24.2\%), and $10(30.3 \%)$ patient were classified as IA, IB, IIA, II B, and III, respectively. All patients that received chemotherapy received doxorubicin and ifosfamide (Table I). Combined treatment with PDS and PDT was performed in $8(42.1 \%)$ patients in the AO group, and that with PDS, PDT and RDT was performed in $11(57.9 \%)$ patients in the AO group.

Among all patients, the AJCC stages in the AO group were significantly worse than those in the non-AO group $(p<0.05)$, and the local recurrence rate in the $\mathrm{AO}$ group was significantly lower than that in the non-AO group $(p<0.05)$ (Table I). Although the Kaplan-Meier OS curves for the two groups did not significantly differ, the LRS curves showed a significant difference $(p<0.05)$ (Figure 1). Outcomes among patients in the AO group were: 8 alive without disease (42.1\%), 3 alive with disease $(15.8 \%)$, and 8 dead $(42.1 \%)$. Outcome in the non-AO group were: 22 alive without disease (66.7\%), 4 alive with disease $(12.1 \%)$, and 7 dead $(21.2 \%)$. There were no significant differences in outcomes between the two groups (Table I). No patients died of complications during the perioperative period. Only among patients with high grade sarcoma, the AJCC stage in the AO group was significantly worse than that in the non-AO group $(p<0.05)$, and the local recurrence rate in the $\mathrm{AO}$ group was significantly lower than that in the non-AO group $(p<0.05)$ (Table II). There were no significant differences in the Kaplan-Meier LRS and OS curves between the two groups (Figure 2). 
Table I. Comparison of patient characteristics between those in the acridine orange (AO) and non-acridine orange (non-AO) groups.

\begin{tabular}{|c|c|c|c|}
\hline & $\mathrm{AO}$ group $(\%)$ & Non-AO group (\%) & p-Value \\
\hline Number & 19 & 33 & \\
\hline Age (years) & $64.4 \pm 15.5$ & $58.4 \pm 18.0$ & 0.229 \\
\hline Gender & & & 0.198 \\
\hline Male/Female & $8 / 11$ & $20 / 13$ & \\
\hline \multicolumn{4}{|l|}{ Histological diagnosis } \\
\hline Undifferentiated pleomorphic sarcoma & $5(26.3)$ & $6(18.2)$ & \\
\hline Myxofibrosarcoma & $4(21.0)$ & $5(15.2)$ & \\
\hline Dedifferentiated liposarcoma & $5(26.3)$ & $6(18.2)$ & \\
\hline Pleomorphic liposarcoma & $0(0)$ & $2(6.1)$ & \\
\hline Myxoid liposarcoma & $1(5.3)$ & $9(27.3)$ & \\
\hline Synovial sarcoma & $3(15.8)$ & $1(3.0)$ & \\
\hline Low malignancy fibromyxosarcoma & $1(5.3)$ & $1(3.0)$ & \\
\hline Extraskeletal myxoid chondrosarcoma & $0(0)$ & $2(6.1)$ & \\
\hline Leiomyosarcoma & $0(0)$ & $1(3.0)$ & \\
\hline Location & & & 0.325 \\
\hline Extremity/Axial & $14 / 5$ & $28 / 5$ & \\
\hline Size $(\mathrm{mm})$ & $106.6 \pm 54.6$ & $95.1 \pm 41.0$ & 0.394 \\
\hline Metastasis at diagnosis & & & 0.778 \\
\hline Present/None & $0 / 19$ & $1 / 32$ & \\
\hline FNCLCC classification & & & 0.109 \\
\hline Grade I & $4(21.1)$ & $11(33.3)$ & \\
\hline Grade II & $3(15.8)$ & $11(33.3)$ & \\
\hline Grade III & $12(63.1)$ & $11(33.3)$ & \\
\hline AJCC stage & & & 0.021 \\
\hline Stages I and II & $7(36.9)$ & $23(69.7)$ & \\
\hline Stages III and IV & $12(63.1)$ & $10(30.3)$ & \\
\hline Chemotherapy & & & 0.709 \\
\hline Present/None & $3 / 16$ & $4 / 29$ & \\
\hline Metastasis after surgery & & & 0.111 \\
\hline Present/None & $10 / 9$ & $10 / 23$ & \\
\hline Local recurrence & & & 0.017 \\
\hline Present/None & $5 / 14$ & $20 / 13$ & \\
\hline Follow-up period (months) & $59.8 \pm 40.8$ & $53.3 \pm 36.0$ & 0.552 \\
\hline Outcome at the last follow-up & & & 0.201 \\
\hline Alive without disease & $8(42.1)$ & $22(66.7)$ & \\
\hline Alive with disease & $3(15.8)$ & $4(12.1)$ & \\
\hline Dead & $8(42.1)$ & $7(21.2)$ & \\
\hline
\end{tabular}

Values are expressed as the number and proportion of patients or means \pm standard deviations (SD) with ranges. AO: Acridine orange; FNCLCC: French Federation of Cancer Center Sarcoma Group; AJCC: American Joint Committee on Cancer.

In the univariate analysis which investigated factors associated with local recurrence, older age, high grade malignancy, and no treatment with $\mathrm{AO}$ were identified as risk factors for local recurrence. Upon multivariate analysis, high grade malignancy and no treatment with $\mathrm{AO}$ were identified as risk factors for local recurrence $(p<0.05$ and $p<0.01)$ (Table III). In the univariate logistic regression analysis, which investigated factors associated with prognosis, only high-grade malignancy affected prognosis $(p<0.05)$.

\section{Discussion}

In the current study, it was demonstrated that $\mathrm{AO}$ administration significantly decreased the local recurrence rate among all STS cases and among only those with highgrade STS when compared with patients with marginal resection who did not receive AO. Additionally, it was shown that the use of AO reduces the risk of local recurrence. Matsubara et al. have reported that there was no significant difference in the local recurrence rate between STS cases that received AO and extensive resection STS cases that did not receive AO; LRS was $71 \%$ among cases that received $\mathrm{AO}$ and those with extensive resection who did not receive AO (8). Nakamura et al. have reported that long-term AO therapy resulted in $78.9 \%$ and $73.3 \%$ 5- and 10-year LRS, respectively (9). In our study, the LRS for all STS patients and for those with high-grade STS only were $73.7 \%$ and $66.7 \%$, respectively. Although somewhat low, the LRS 
Table II. Characteristics of the patients with high grade sarcoma between the acridine orange (AO) and non-acridine orange (non-AO) groups.

\begin{tabular}{|c|c|c|c|}
\hline & $\mathrm{AO}$ group $(\%)$ & Non-AO group $(\%)$ & $p$-Value \\
\hline Number & 15 & 22 & \\
\hline Age & $63.7 \pm 16.9$ & $67.8 \pm 14.1$ & 0.427 \\
\hline Gender & & & 0.457 \\
\hline Male/Female & $7 / 8$ & $13 / 9$ & \\
\hline \multicolumn{4}{|l|}{ Histological type } \\
\hline Undifferentiated pleomorphic sarcoma & $5(33.3)$ & $6(27.3)$ & \\
\hline Myxofibrosarcoma & $2(13.4)$ & $4(18.2)$ & \\
\hline Dedifferentiated liposarcoma & $5(33.3)$ & $6(27.3)$ & \\
\hline Pleomorphic liposarcoma & $0(0)$ & $2(9.1)$ & \\
\hline Myxoid liposarcoma & $0(0)$ & $2(9.1)$ & \\
\hline Synovial sarcoma & $3(20.0)$ & $0(0)$ & \\
\hline Extraskeletal myxoid chondrosarcoma & $0(0)$ & $1(4.5)$ & \\
\hline Leiomyosarcoma & $0(0)$ & $1(4.5)$ & \\
\hline Location & & & 0.153 \\
\hline Extremity/Axial & $10 / 5$ & $19 / 3$ & \\
\hline Size $(\mathrm{mm})$ & $115.0 \pm 58.6$ & $88.6 \pm 43.6$ & 0.125 \\
\hline Metastasis at diagnosis & & & 0.403 \\
\hline Present/None & $0 / 15$ & $1 / 21$ & \\
\hline FNCLCC classification & & & 0.065 \\
\hline Grade II & $3(20.0)$ & $11(50.0)$ & \\
\hline Grade III & $12(80.0)$ & $11(50.0)$ & \\
\hline AJCC stage & & & 0.036 \\
\hline Stage II & $3(20.0)$ & $12(54.5)$ & \\
\hline Stage III & $12(80.0)$ & $10(45.5)$ & \\
\hline Chemotherapy & & & 0.341 \\
\hline Present/None & $3 / 12$ & $2 / 20$ & \\
\hline Metastasis after surgery & & & 0.157 \\
\hline Present/None & $9 / 6$ & $8 / 14$ & \\
\hline Local recurrence & & & 0.037 \\
\hline Present/None & $5 / 10$ & $15 / 7$ & \\
\hline Follow-up period (months) & $50.5 \pm 36.2$ & $44.9 \pm 33.3$ & 0.629 \\
\hline Outcome at the last follow-up & & & 0.388 \\
\hline Alive without disease & $5(33.3)$ & $12(54.5)$ & \\
\hline Alive with disease & $2(13.4)$ & $3(13.7)$ & \\
\hline Dead & $8(53.3)$ & $7(31.8)$ & \\
\hline
\end{tabular}

Values are expressed as the number and proportion of patients or means \pm standard deviations (SD) with ranges. AO: Acridine orange; FNCLCC: French Federation of Cancer Center Sarcoma Group; AJCC: American Joint Committee on Cancer.

detected in this study was similar to that from past reports. Additionally, a histologic high-grade was a risk factor for local recurrence. Patients in the AO group showed a high tendency for malignancy and frequently had grade III malignancy; this relationship existed even among those with high-grade STS only. Despite the fact that the histological grade was worse in the AO group than in the non-AO group, the effectiveness of $\mathrm{AO}$ on local recurrence was demonstrated. Conversely, in the case of partial marginal resection without AO or adjuvant therapy, LRS for all STS patients and those with only high-grade STS was $39.4 \%$ and $31.8 \%$, respectively, and high local recurrence rates were shown. Based on our findings, we should be considered AO therapy for STS patients with expected marginal resection before surgery, and adjuvant therapy such as radiotherapy should be strongly recommended for cases in which marginal resection is suspected histopathologically after surgery.

Although there was no significant difference in OS, a slightly lower trend was seen in the AO group. Matsubara et al. have reported that there was no significant difference in OS between STS cases that received AO and extensive resection STS cases who did not receive AO; the OS in cases that received $\mathrm{AO}$ and extensive resection cases were $68 \%$ and $63 \%$, respectively (8). However, based on our findings, the $\mathrm{OS}$ in the $\mathrm{AO}$ group was a little lower. Factors, such as older age, larger tumor size, high histological grade, and non-surgical treatment, have been identified as significant independent adverse prognostic factors (18-26). In the current study, high-grade sarcoma tended to be higher in the AO group, and grade III was 
a

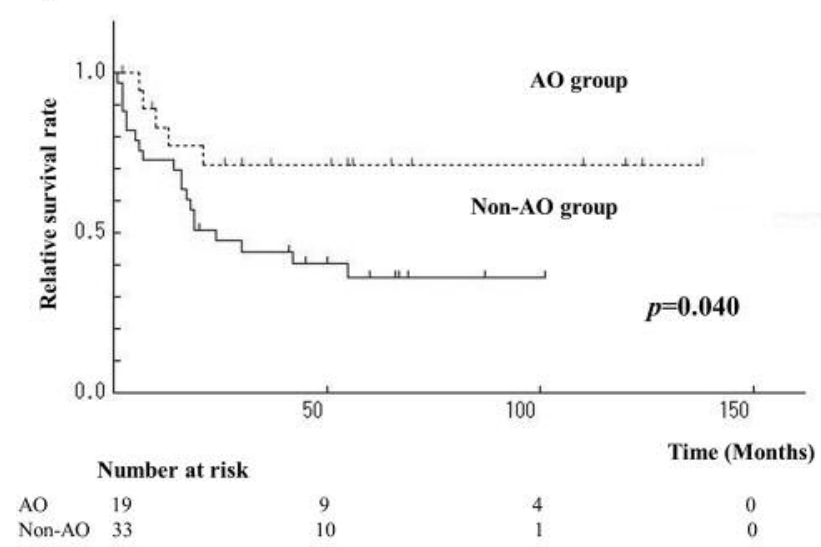

b

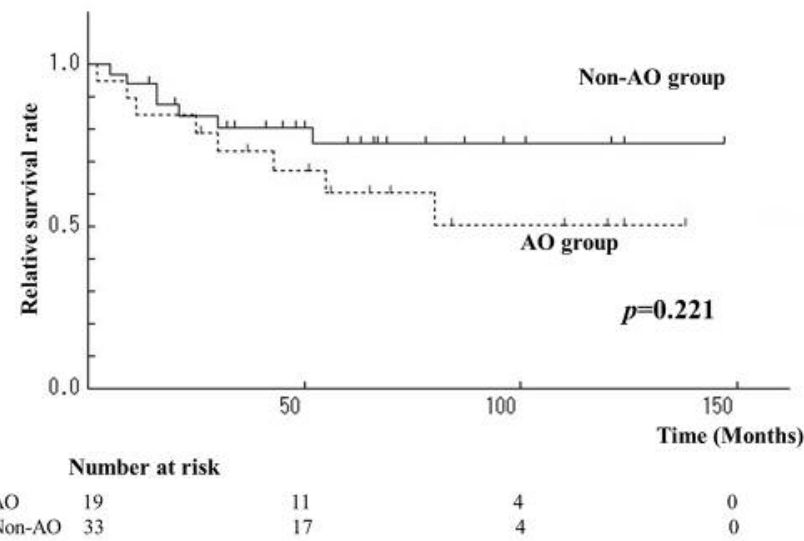

Figure 1. Kaplan-Meier local recurrence-free survival curves $(a)$ and overall survival curves (b) based on the use of acridine orange (AO) in all patients. A significant difference was shown between the two groups in local recurrence-free survival $(p=0.040)(a)$. AO: Acridine orange.

a

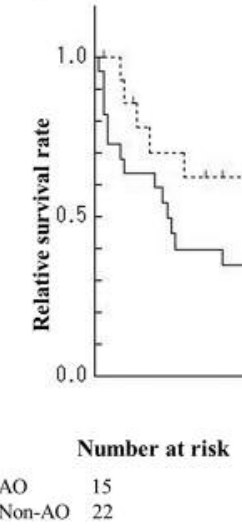
Non-AO 22

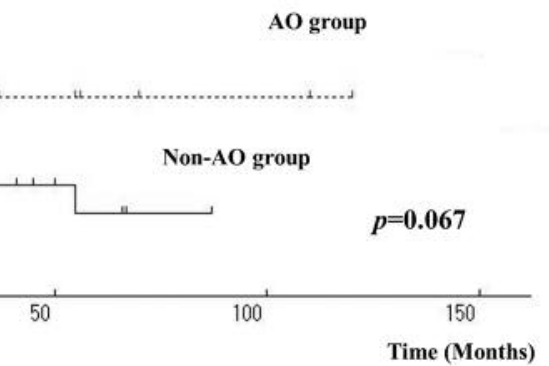

5 Time (Months) $\begin{array}{ll}5 & 2 \\ 5 & 0\end{array}$

b

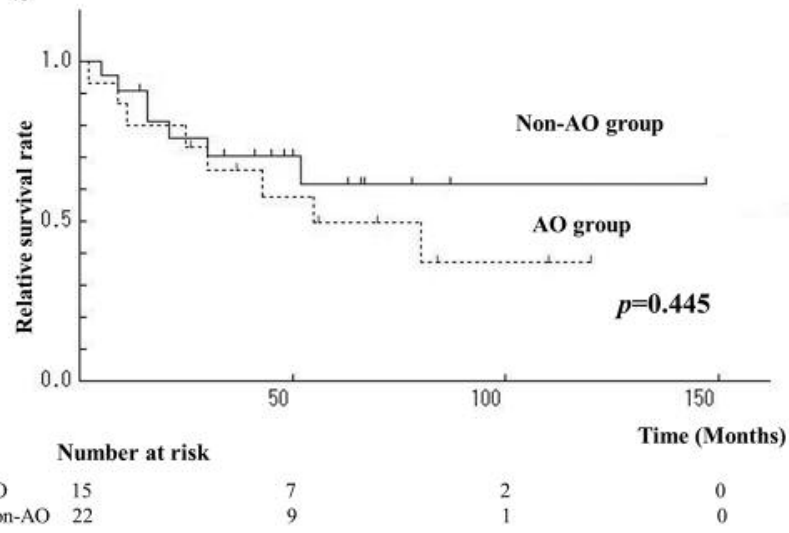

Figure 2. Kaplan-Meier local recurrence-free survival curves (a) and overall survival curves (b) based on the use of acridine orange (AO) in patients with high grade sarcoma. No significant difference was shown between the two groups. AO: Acridine orange.

more common in the AO group. This may have lowered the prognosis in the AO group. Additionally, there have been some reports in which local recurrence was not associated with prognosis, in fact, the influence on prognosis may be weak (18-22). The 5-year OS rates in a large series of patients with high-grade STS ranged from $66 \%$ to $76 \%$, and the OS of our marginal resection patients without $\mathrm{AO}$ was not significantly inferior (23-26). The frequency of highhistological malignancy, distant metastasis after tumor resection, and death was relatively high despite the small number cases that received AO. This relationship needs to be further explored by including larger numbers of cases in the future.

Although adjuvant radiotherapy has also been reported to assist in improving prognosis, some studies have reported that the effects of radiotherapy were not superior to those of extensive resection $(25,27-29)$. Additionally, the frequency of complications is high, and it is easy for complications to arise as a result of surgical wounds due to radiotherapy before surgery and fibrosis due to radiotherapy after surgery, thus causing dysfunction $(30,31)$. Although radiation is also applied to RDT, the dose of $5 \mathrm{~Gy}$ is small, and there have been no reports of complications to date. Nakamura et al. have shown the possibility of RDT efficacy in patients with intralesional resection; additionally, they have shown that RDT may be necessary to prevent local recurrence in addition to PDT (9).

AO is recommended not only for its effects on the surgical site but also for its effects following intravenous administration. It has been reported that lung metastasis was 
Table III. Univariate and multivariate analysis of the factors affecting local recurrence and prognosis.

\begin{tabular}{|c|c|c|c|c|c|c|}
\hline \multirow[t]{2}{*}{ Variables } & \multicolumn{3}{|c|}{ Univariate } & \multicolumn{3}{|c|}{ Multivariate } \\
\hline & OR & $95 \% \mathrm{CI}$ & $p$-Value & OR & $95 \% \mathrm{CI}$ & $p$-Value \\
\hline \multicolumn{7}{|l|}{ Local recurrence } \\
\hline Age & 1.026 & $1.001-1.052$ & 0.039 & 1.011 & $0.981-1.042$ & 0.488 \\
\hline Gender & 0.917 & $0.418-2.010$ & 0.828 & & & \\
\hline Location & 1.319 & $0.525-3.312$ & 0.556 & & & \\
\hline Size & 0.999 & $0.990-1.008$ & 0.794 & & & \\
\hline FNCLCC classification & 1.956 & $1.152-3.323$ & 0.013 & 2.303 & $1.124-4.719$ & 0.023 \\
\hline Acridine orange & 0.374 & $0.140-0.999$ & 0.049 & 0.241 & $0.086-0.674$ & 0.007 \\
\hline Chemotherapy & 1.172 & $0.402-3.420$ & 0.771 & & & \\
\hline \multicolumn{7}{|l|}{ Prognosis } \\
\hline Age & 1.024 & $0.989-1.060$ & 0.182 & & & \\
\hline Gender & 1.310 & $0.434-3.954$ & 0.631 & & & \\
\hline Location & 0.928 & $0.207-4.162$ & 0.922 & & & \\
\hline Size & 0.993 & $0.980-1.007$ & 0.321 & & & \\
\hline Metastasis at diagnosis & 2.618 & $0.321-21.326$ & 0.369 & & & \\
\hline FNCLCC classification & 4.057 & $1.111-14.817$ & 0.034 & & & \\
\hline Acridine orange & 2.366 & $0.797-6.536$ & 0.124 & & & \\
\hline Chemotherapy & 0.923 & $0.288-2.957$ & 0.892 & & & \\
\hline Local Recurrence & 1.778 & $0.546-5.784$ & 0.339 & & & \\
\hline
\end{tabular}

OR: Odds ratio; 95\%CI: 95\% confidence interval; FNCLCC: French Federation of Cancer Center Sarcoma Group.

suppressed by intravenous administration of $\mathrm{AO}$ to an osteosarcoma mouse model (32). Additionally, a clinical trial of radiotherapy after intravenous injection of $\mathrm{AO}$ in patients with advanced cancer is ongoing (10); results for this will released in the future.

One of the main limitations in this study was the small number of patients. Several factors may have led to biases, such as histological malignancy, size, and location; a larger number of patients are needed to sufficiently analyze these factors. If we judge that we have a marginal resection, we often conduct adjuvant therapies such as radiotherapy. Therefore, only patients with STS of low-grade malignancy or those who refuse radiotherapy would be included to the control group. Second, the extent of marginal resection may affect prognoses, however we could not accurately evaluate this in this study. Patients in the AO group were expected to require marginal resection before surgery, and the area of marginal resection may be wider than that in the nonAO group. There is a need to perform further detailed studies which will evaluate the extent of the marginal resection area.

The present study showed the strong inhibitory effect of AO therapy on local recurrence after marginal resection of STS. AO therapy should be considered for STS patients expected to require marginal resection before surgery. Although there was no improvement in prognosis, we need to perform further detailed studies including a larger number of patients to confirm these findings.

\section{Conflicts of Interest}

Hiroyuki Tsuchie received funding from a research grant foundation that may be affected by the research reported in this paper.

\section{Authors' Contributions}

All Authors were involved in the planning and revising for this research. Tsuchie $H$, Nagasawa $H$, Emori $M$, Murahasi $Y$, Mizushima E, and Shimizu J collected the clinical data. Tsuchie $\mathrm{H}$ analyzed the raw data. Tsuchie H wrote this study. Miyakoshi N, Okada K, Yamashita Y, and Shimada Y reviewed this manuscript.

\section{Acknowledgements}

This work was supported by the Japan orthopedics and traumatology foundation, Inc. under Grant (number: 390).

\section{References}

1 Haas RL, Delaney TF, O'Sullivan B, Keus RB, Le Pechoux C, Olmi P, Poulsen JP, Seddon B and Wang D: Radiotherapy for management of extremity soft tissue sarcomas: why, when, and where? Int J Radiat Oncol Biol Phys 84(3): 572-8084: 572-580, 2012. PMID: 22520481. DOI: 10.1016/j.ijrobp.2012.01.062

2 Kneisl JS, Ferguson C, Robinson M, Crimaldi A, Ahrens W, Symanowski J, Bates M, Ersek JL, Livingston M, Patt J and Kim ES: The effect of radiation therapy in the treatment of adult soft tissue sarcomas of the extremities: a long-term communitybased cancer center experience. Cancer Med 6(3): 516-525, 2017. PMID: 28188703. DOI: 10.1002/cam4.972 
3 Davis AM, O'Sullivan B, Turcotte R, Bell R, Catton C, Chabot P, Wunder J, Hammond A, Benk V, Kandel R, Goddard K, Freeman C, Sadura A, Zee B, Day A, Tu D and Pater J; Canadian Sarcoma Group; NCI Canada Clinical Trial Group Randomized Trial: Late radiation morbidity following randomization to preoperative versus postoperative radiotherapy in extremity soft tissue sarcoma. Radiother Oncol 75(1): 48-53, 2005. PMID: 15948265. DOI: 10.1016/j.radonc.2004.12.020

4 Kusuzaki K, Murata H, Matsubara T, Miyazaki S, Okamura A, Seto M, Matsumine A, Hosoi H, Sugimoto T and Uchida A: Clinical trial of photodynamic therapy using acridine orange with/without low dose radiation as new limb salvage modality in musculoskeletal sarcomas. Anticancer Res 25(2B): 1225-1235, 2005. PMID: 15865070.

5 Nakamura T, Kusuzaki K, Matsubara T, Matsumine A, Murata H and Uchida A: A new limb salvage surgery in cases of high-grade soft tissue sarcoma using photodynamic surgery, followed by photoand radiodynamic therapy with acridine orange. J Surg Oncol 97(6): 523-528, 2008. PMID: 18348188. DOI: 10.1002/jso.21025

6 Matsubara T, Kusuzaki K, Matsumine A, Murata H, Satonaka H, Shintani K, Nakamura T, Hosoi H, Iehara T, Sugimoto T and Uchida A: A new therapeutic modality involving acridine orange excitation by photon energy used during reduction surgery for rhabdomyosarcomas. Oncol Rep 21(1): 89-94, 2009. PMID: 19082447

7 Matsubara T, Kusuzaki K, Matsumine A, Murata H, Nakamura T, Uchida A and Sudo A: Clinical outcomes of minimally invasive surgery using acridine orange for musculoskeletal sarcomas around the forearm, compared with conventional limb salvage surgery after wide resection. J Surg Oncol 102(3): 271275, 2010. PMID: 20740586. DOI: 10.1002/jso.21602

8 Matsubara T, Kusuzaki K, Matsumine A, Nakamura T and Sudo A: Can a less radical surgery using photodynamic therapy with acridine orange be equal to a wide-margin resection? Clin Orthop Relat Res 471(3): 792-802, 2013. PMID: 23008027. DOI: 10.1007/s11999-012-2616-9

9 Nakamura T, Kusuzaki K, Matsubara T, Murata H, Hagi T, Asanuma $\mathrm{K}$ and Sudo A: Long-term clinical outcome in patient with high-grade soft tissue sarcoma who were treated with surgical adjuvant therapy using acridine orange after intra-lesional or marginal resection. Photodiagnosis Photodyn Ther 23: 165-170, 2018. PMID: 29885811. DOI: 10.1016/j.pdpdt.2018.06.001

10 Kusuzaki K, Takai T, Yoshimura H, Inoue K, Takai S and Baldini $\mathrm{N}$ : Clinical trial of radiotherapy after intravenous injection of acridine orange for patients with cancer. Anticancer Res 38(1): 481-489, 2018. PMID: 29277813. DOI: 10.21873/anticanres.12248

11 Kusuzaki K, Aomori K, Suginoshita T, Minami G, Takeshita H, Murata $\mathrm{H}$, Hashiguchi $\mathrm{S}$, Ashihara $\mathrm{T}$ and Hirasawa $\mathrm{Y}$ : Total tumor cell elimination with minimum damage to normal tissues in musculoskeletal sarcomas following photodynamic therapy with acridine orange. Oncology 59(2): 174-180, 2000. PMID 10971178. DOI: $10.1159 / 000012156$

12 Kusuzaki K, Murata H, Takeshita H, Hashiguchi S, Nozaki T, Emoto K, Ashihara T and Hirasawa Y: Intracellular binding sites of acridine orange in living osteosarcoma cells. Anticancer Res 20(2A): 971-975, 2000. PMID: 10810383.

13 Kusuzaki K, Suginoshita T, Minami G, Aomori K, Takeshita H, Murata H, Hashiguchi S, Ashihara T and Hirasawa Y: Fluorovisualization effect of acridine orange on mouse osteosarcoma. Anticancer Res 20(5A): 3019-3024, 2000. PMID: 11062717.
14 Kusuzaki K, Takeshita H, Murata H, Gebhardt MC, Springfield DS, Mankin HJ, Ashihara T and Hirasawa Y: Polyploidization induced by acridine orange in mouse osteosarcoma cells. Anticancer Res 20(2A): 965-970, 2000. PMID: 10810382.

15 Matsubara T, Kusuzaki K, Matsumine A, Shintani K, Satonaka $\mathrm{H}$ and Uchida A: Acridine orange used for photodynamic therapy accumulates in malignant musculoskeletal tumors depending on $\mathrm{pH}$ gradient. Anticancer Res 26(1A): 187-193, 2006. PMID: 16475697.

16 Edge SB and Compton CC: AJCC cancer staging handbook. 7th ed, Springer, New York; Springer 2010.

17 Coindre JM, Terrier P, Bui NB, Bonichon F, Collin F, Le Doussal V, Mandard AM, Vilain MO, Jacquemier J, Duplay H, Sastre X, Barlier C, Henry-Amar M, Macé-Lesech J and Contesso G: Prognostic factors in adult patients with locally controlled soft tissue sarcoma. A study of 546 patients from the French Federation of Cancer Centers Sarcoma Group. J Clin Oncol 14(3): 869-877, 1996. PMID: 8622035. DOI: 10.1200/JCO.1996.14.3.869

18 Buchner M, Bernd L, Zahlten-Hinguranage A and Sabo D: Primary malignant tumours of bone and soft tissue in the elderly. Eur J Surg Oncol 30(8): 877-883, 2004. PMID: 15336735. DOI: $10.1016 /$ j.ejso.2004.06.013

19 Boden RA, Clark MA, Neuhaus SJ, Neuhaus SJ, A'hern JR, Thomas JM and Hayes AJ: Surgical management of soft tissue sarcoma in patients over 80 years. Eur J Surg Oncol 32(10): 11541158, 2006. PMID: 16872801. DOI: 10.1016/j.ejso.2006.05.016

20 Lahat G, Dhuka AR, Lahat S, Lazar AJ, Lewis VO, Lin PP, Feig B, Cormier JN, Hunt KK, Pisters PW, Pollock RE and Lev D: Complete soft tissue sarcoma resection is a viable treatment option for select elderly patients. Ann Surg Oncol 16(9): 2579-2586, 2009. PMID: 19557478. DOI: 10.1245/s10434-009-0574-6

21 Al-Refaie WB, Habermann EB, Dudeja V, Vickers SM, Tuttle TM, Jensen EH and Virnig BA: Extremity soft tissue sarcoma care in the elderly: insights into the generalizability of NCI Cancer Trials. Ann Surg Oncol 17(7): 1732-1738, 2010. PMID: 20354801. DOI: 10.1245/s10434-010-1034-Z

22 Tsuchie H, Emori M, Nagasawa H, Miyakoshi N, Murahashi Y, Mizushima E, Yamashita $\mathrm{T}$ and Shimada Y: The prognostic significance of surgical treatment for excessive elderly patients with soft tissue sarcoma. Int J Clin Oncol 23(4): 775-782, 2018. PMID: 29488145. DOI: $10.1007 / \mathrm{s} 10147-018-1255-\mathrm{x}$

23 Gustafson P: Soft tissue sarcoma. Epidemiology and prognosis in 508 patients. Acta Orthop Scand Suppl 259: 1-31, 1994. PMID: 8042499 .

24 Parsons HM, Habermann EB, Tuttle TM and Al-Refaie WB: Conditional survival of extremity soft-tissue sarcoma: results beyond the staging system. Cancer 117(5): 1055-1060, 2011. PMID: 20960489. DOI: 10.1002/cncr.25564

25 Pisters PW, Leung DH, Woodruff J, Shi W and Brennan MF: Analysis of prognostic factors in 1,041 patients with localized soft tissue sarcomas of the extremities. J Clin Oncol 14(5): 1679-1689, 1996. PMID: 8622088. DOI: 10.1200/JCO.1996.14.5.1679

26 Trovik CS, Bauer HC, Alvegård TA, Anderson H, Blomqvist C, Berlin O, Gustafson P, Saeter G and Wallöe A: Surgical margins, local recurrence and metastasis in soft tissue sarcomas: 559 surgically-treated patients from the Scandinavian Sarcoma Group Register. Eur J Cancer 36(6): 710-716, 2000. PMID: 10762742. DOI: 10.1016/s0959-8049(99)00287-7

27 Herbert SH, Corn BW, Solin LJ, Lanciano RM, Schultz DJ, McKenna WG and Coia LR: Limb-preserving treatment for soft 
tissue sarcomas of the extremities. The significance of surgical margins. Cancer 72(4): 1230-1238, 1993. PMID: 8339214. DOI: 10.1002/1097-0 142(199308 15)72:4<1230::aid-cncr282 $0720416>3.0 . c 0 ; 2-\mathrm{j}$

28 Kawaguchi N, Matumoto S and Manabe J: New method of evaluating the surgical margin and safety margin for musculoskeletal sarcoma, analysed on the basis of 457 surgical cases. J Cancer Res Clin Oncol 121(9-10): 555-663, 1995. PMID: 7559736.

29 Pisters PW, Harrison LB, Leung DH, Woodruff JM, Casper ES and Brennan MF: Long-term results of a prospective randomized trial of adjuvant brachytherapy in soft tissue sarcoma. J Clin Oncol 14(3): 859-868, 1996. PMID: 8622034. DOI: 10.1200/ JCO.1996.14.3.859

30 O'Sullivan B, Davis AM, Turcotte R, Bell R, Catton C, Chabot P, Wunder J, Kandel R, Goddard K, Sadura A, Pater J and Zee B: Preoperative versus postoperative radiotherapy in soft-tissue sarcoma of the limbs: a randomised trial. Lancet 359(9325): 2235-2241, 2002. PMID: 12103287. DOI: 10.1016/S01406736(02)09292-9
31 Stevenson MG, Ubbels JF, Slump J, Huijing MA, Bastiaannet E, Pras E, Hoekstra HJ and Been LB: Identification of predictors for wound complications following preoperative or postoperative radiotherapy in extremity soft tissue sarcoma. Eur J Surg Oncol 44(6): 816-822, 2018. PMID: 29472042. DOI: 10.1016/j.ejso. 2018.02.002

32 Satonaka H, Kusuzaki K, Akeda K, Tsujii M, Iino T, Uemura T, Matsubara T, Nakamura T, Asanuma K, Matsumine A and Sudo A: Acridine orange inhibits pulmonary metastasis of mouse osteosarcoma. Anticancer Res 31(12): 4163-4168, 2011. PMID: 22199275.
Received September 4, 2019

Revised September 19, 2019

Accepted September 23, 2019 